\title{
Growth and enduring epidemic diseases
}

\section{Working Paper}

Author(s):

Bell, Clive; Gersbach, Hans

Publication date:

2006

Permanent link:

https://doi.org/10.3929/ethz-a-005273085

Rights / license:

In Copyright - Non-Commercial Use Permitted

Originally published in:

Economics Working Paper Series 2006(57) 


\title{
CER-ETH - Center of Economic Research at ETH Zurich
}

\section{Growth and Enduring Epidemic Diseases}

\author{
Clive Bell \\ Hans Gersbach \\ Working Paper 06/57 \\ October 2006
}

\section{Economics Working Paper Series}

\section{EIH}

Eidgenössische Technische Hochschule Zürich Swiss Federal Institute of Technology Zurich 


\title{
Growth and Enduring Epidemic Diseases*
}

\author{
Clive Bell \\ Südasien-Institut and the World Bank \\ University of Heidelberg \\ INF 330 \\ D-69120 Heidelberg, Germany \\ clive.bell@urz.uni-heidelberg.de
}

\author{
Hans Gersbach \\ CER-ETH Center for Economic Research at ETH \\ ETH and CEPR \\ 8032 Zurich, Switzerland \\ hgersbach@ethz.ch
}

First version: May 2004

This version: May 2006

\begin{abstract}
This paper studies the formation of human capital and its transmission across generations when premature adult mortality is a salient feature of the demographic landscape, either permanently or in the form of a long-period wave that follows the outbreak of an epidemic. We establish several threshold properties of the model, for such a shock can severely retard economic growth, even to the point of leading to an economic collapse. Premature adult mortality may exacerbate inequality under nuclear family arrangements. Pooling mortality risks with equal treatment of all children may fend off, or even induce, a collapse, depending on the initial conditions and the size and duration of the shock. Awareness campaigns may also trigger a collapse by introducing undesirable expectational feedbacks.
\end{abstract}

Keywords: Epidemic Diseases, HIV/AIDS, Growth, Collapse, Pooling

JEL Classification: I10, I20, O11, O40

\footnotetext{
${ }^{*}$ We thank Bernhard Pachl, Ramona Bruhns, Noemi Hummel, Maik Schneider, Martin Scheffel, Lars Siemers and participants in seminars at Berkeley, Cornell, Heidelberg and the World Bank for their valuable comments and suggestions.
} 


\section{Introduction}

The great historical epidemic that springs to the European mind is the Black Death. Sweeping through Europe between 1347 and 1351, the Plague carried off about one-third of the entire population. It has been argued that this demographic catastrophe undermined the feudal system and freed these societies from the burden of overpopulation. McNeill (1976) and other historians have argued that great plagues also left a cultural and psychological legacy of despair and pessimism. This latter thesis is vigorously challenged by Cohn (2003), who observes that the Plague was soon followed not only by the general optimism and individualism of the Renaissance, but also by the growing conviction, in medical and literate circles at least, that the Plague's causes lay not in God's wrath or the position of the stars, but rather in this natural world.

The great modern plague is HIV/AIDS; but there are some striking differences between the two diseases. The Black Death carried off rich and poor, and young and old alike, usually in a matter of days. AIDS is selective, and its individual course is both lengthy and, until the end stages, free of symptoms. Its victims are overwhelmingly young adults and those in early middle-age, the great majority with children to raise and care for. This selectivity is fundamental; for if parents die while their children are still young, then all the means needed to raise the children so that they can become productive and capable citizens will be greatly reduced. The affected families' lifetime income will shrink, and thus the means to finance education. The children will also lose the love, knowledge and guidance which complement formal education. AIDS does much more, therefore, than destroy the existing abilities and capacities embodied in its victims; it also weakens the mechanism through which human capital is formed in the next generation and beyond. These ramifications will take decades to make themselves fully felt. Like the course of the disease in individuals, they are long-drawn out and insidious. All the while, the growing burden on surviving adults can threaten fiscal stability and institutions like the extended family, and the incessant reminders of an untimely death can seize society with a pessimism that hinders provision for the future.

Motivated by the character of the AIDS epidemic, the purpose of this paper is to develop 
a framework that focuses on the transmission of human capital between generations when premature adult mortality is a salient feature of the demographic landscape, either permanently or in the form of a long-period wave that follows the initial outbreak of an epidemic. Such a framework is also applicable to, inter alia, tuberculosis, whose incidence is closely connected to that of AIDS and which is also responsible for a large part of the so-called burden of disease in poor countries. The framework's basic elements are as follows. Parents have preferences over current consumption and the level of human capital attained by their children, making due allowance for early mortality when the children reach adulthood. The decision about how much to invest in education, as the alternative to child labour, is influenced by premature adult mortality in two ways. First, in the present, the family's lifetime income depends on the adults' health status and longevity. Second, the expected pay-off depends on the level of premature mortality in the future. An increase in such mortality may result in a progressive collapse of human capital and productivity, depending on how how sharp it is, how long it is sustained and how expectations are formed.

One important effect of an increase in premature adult mortality is to exacerbate inequality, if only initially, in nuclear family systems. For if orphaned children are not given the care and education enjoyed by those with parents, the weakening of the inter-generational transmission mechanism will express itself in increasing inequality among the next generation of adults and the families they form. An alternative form of social organization is the extended family, whose surviving adults take in related orphans. Such a pooling arrangement might protect a society from a collapse. We show that pooling puts the society on a "make or break" road in the following sense. Pooling can lead to a collapse which might otherwise be avoidable, especially if the epidemic causes quite severe mortality. In a less lethal disease environment, in contrast, pooling is a form of social organization that helps fend off a collapse that would occur under a nuclear family structure.

This paper is related to various strands in the literature. First, there is the general empirical observation that good health has a positive and statistically significant effect on aggregate output (Barro and Sala-I-Martin, 1995; Bloom and Canning, 2000; Bloom, Canning and Sevilla, 2001). The report of the Commission on Macroeconomics and Health (WHO, 2001) also stresses that widespread diseases are a formidable barrier to economic growth. Second, 
there are studies of the macroeconomic effects of AIDS. Papers that adopt an OLG framework have chosen somewhat different points of emphasis. In our model, higher mortality risk undermines the formation of human capital through three channels: first, if one or both parents die early, their children will have less productive capacity, as less human capital is transmitted; second, the loss of income due to early death in a family reduces schooling; third, the chance that the children themselves will be infected as adults makes investment in their education less attractive. Corrigan, Glomm and Méndez (2004, 2005) consider only the first two channels, but they allow for effects on the accumulation of physical capital, which are absent in our model. Hence, our paper complements theirs in establishing how AIDS might influence the course of per capita income. A notable recent paper that adopts a Solovian structure is Young (2005), which estimates the impact of the AIDS epidemic on future living standards in South Africa through its effects on schooling and fertility, with a constant savings rate. Young finds that the reduction in labor supply heavily outweighs the damage done to human capital accumulation, so that using per capita living standards as the yardstick, the epidemic is a boon to the generations which survive and succeed it.

Third, there is the recent literature on economic growth in which the transition through different regimes is endogenously generated. This was initiated by Galor and Weil (1999, 2000), who describe, within a unified framework, long-run development processes from an epoch of Malthusian stagnation to a state of sustained economic growth in modern times. We focus, in contrast, on how some epidemics may induce a transition from a state of continuous growth to a state of backwardness and poverty. Our paper is complementary to the recent illuminating contribution of Chakraborty (2004), who studies endogenous mortality in an overlapping generations model. He shows how better health, by improving longevity and reducing the risks of mortality, is conducive to growth, and points to health investment as a prerequisite for sustaining growth. Another related paper is Lagerlöf (2003), who examines the long-run development process in Western Europe, with particular attention to epidemic shocks that affect child mortality. He shows that a series of mild shocks causes a transition from a Malthusian stage to the Industrial Revolution, since population does not expand so rapidly as it would otherwise, thereby raising productivity in human capital production and income growth. In our framework, a negative epidemic shock affects parents when young, 
so interrupting the transmission of human capital across generations, whereas in Lagerlöf (2003), epidemic diseases might actually spur growth.

The plan of the paper is as follows. The basic model, which builds on Bell and Gersbach (2001) and Bell, Devarajan and Gersbach (2003) by combining epidemiological and economic dynamics, is set out in Section 2. The dynamics of the system under both stationary and non-stationary mortality profiles are analyzed in Section 3, paying special attention to the conditions for an economic collapse to occur. We illustrate plausible time paths by means of an example in Section 4. In Section 5 we examine pooling as an alternative form of organization that has both advantages and drawbacks in such a setting. In Section 6 we show that awareness campaigns may introduce some undesirable tradeoffs when a government wants to promote the understanding of how an epidemic evolves. A proper understanding of the causes of the disease may help to reduce the current risk of infection, but it may also induce an upward revision of expected mortality, which may trigger a collapse. The concluding section is devoted to an assessment and applications of the overall results and the most fruitful directions of future research.

\section{The Model}

There are two periods of life, childhood and adulthood. On becoming adults, individuals immediately form families and have children, who, when very young, neither work nor attend school. Since the only form of investment is education, the family's full income is wholly consumed in this phase. Only afterwards do the adults learn whether they will die prematurely, and so leave their children as half- or full orphans. Early in each generation of adults, therefore, all nuclear families are sorted into one of the following four categories: both parents survive into old age, the father dies prematurely, the mother dies prematurely, both parents die prematurely. These states are denoted by $s_{t} \in S_{t}:=\{1,2,3,4\}$, respectively. The probability that a family formed at the start of period $t$ lands in category $s_{t}$ is denoted by $\pi_{t}\left(s_{t}\right)$. The population is large enough that this is also the fraction of all families in that state after all premature adult deaths have occurred. An important consequence 
of such mortality is that it results in heterogeneity among each cohort of families. Once its state has been revealed, a family makes its decisions accordingly, where the surviving adults' expectations concerning the future levels of the state probabilities play a potentially crucial role.

Let $\lambda_{t}^{f}$ and $\lambda_{t}^{m}$ denote, respectively, the father's and mother's endowments of human capital, and let $\Lambda_{t}\left(s_{t}\right)$ denote their total human capital when the family is in state $s_{t}$. Then,

$$
\Lambda_{t}(1)=\lambda_{t}^{f}+\lambda_{t}^{m}, \Lambda_{t}(2)=\lambda_{t}^{m}, \Lambda_{t}(3)=\lambda_{t}^{f}, \Lambda_{t}(4)=0 .
$$

How the partners are matched can affect heterogeneity in the population in future periods, and hence the behavior of the whole system. Some sort of assortative mating is a major feature of most epidemiological models (e.g., Mulder and Johnson, 2005). The following 'rule' simplifies the analysis:

Assumption 1. There is strict assortative mating: $\lambda_{t}^{f}=\lambda_{t}^{m} \forall t$.

Under Assumption 1, eq. (1) specializes to

$$
\Lambda_{t}(1)=2 \lambda_{t}, \Lambda_{t}(2)=\Lambda_{t}(3)=\lambda_{t}, \Lambda_{t}(4)=0,
$$

where the superscripts $f$ and $m$ may be dropped without introducing ambiguity.

Human capital is assumed to be formed by a process of child-rearing combined with formal education in the following way. In the course of rearing their children, parents give them a certain capacity to build human capital for adulthood, a capacity which is itself increasing in the parents' own human capital. This gift will be of little use, however, unless it is complemented by at least some formal education. Let the proportion of childhood devoted to education be denoted by $e_{t} \in[0,1]$, the residual being allocated to work, and for simplicity, let all the children in a family be treated in the same way. Expressed formally, the human capital attained by each of the children on reaching adulthood is assumed to be given by

$$
\lambda_{t+1}= \begin{cases}z\left(s_{t}\right) f\left(e_{t}\right) \Lambda_{t}\left(s_{t}\right)+1, & s_{t}=1,2,3 \\ \xi(\leq 1) & s_{t}=4\end{cases}
$$

The term $z\left(s_{t}\right)$ represents the strength with which capacity is transmitted across generations. It is plausible that the father's and mother's contributions to this process are not perfect 
substitutes, in which case, $2 z(1)>\max [z(2), z(3)]$, and $z(2)$ may not be equal to $z(3)$. For simplicity, however, we restrict the possibilities as follows:

Assumption 2. $z(2)=z(3) \geq z(1) \geq z(2) / 2=z(3) / 2>0$.

If the parents are perfect complements, then $z(1)=z(2)=z(3)$; if perfect substitutes, then $2 z(1)=z(2)=z(3)$. Assumptions 1 and 2 allow the upper branch of (2) to be rewritten as

$$
\lambda_{t+1}=\left(3-s_{t}\right) z\left(s_{t}\right) f\left(e_{t}\right) \lambda_{t}+1, \quad s_{t}=1,2
$$

Since both types of single-parent families $\left(s_{t}=2,3\right)$ are identical in this respect, we may omit $s_{t}=3$.

The function $f(\cdot)$ may be thought of as representing the educational technology. The only restrictions we impose on it are summarized in:

Assumption 3. $f(\cdot)$ is a continuous, strictly increasing and differentiable function on $[0,1]$, with $f(0)=0$.

Observe that Assumption 3 implies that children who do not attend school at all attain, as adults, only some basic level of human capital, which has been normalized to unity. A whole society of such adults will be said to be in a state of economic backwardness.

We now turn to the lower branch of (2). According to this branch, there is a miserable outcome for full orphans who do not enjoy the good fortune of being adopted or placed in (good) institutional care. Deprived of love and care, and left to their own devices, they go through childhood uneducated, to attain human capital $\xi$ in adulthood. For convenience, we set $\xi=1$. Diseases that increase orphanhood, combined with the technical condition $f(0)=0$, therefore constitute a potentially powerful threat to long-term economic growth.

Output takes the form of an aggregate consumption good. The following assumption implies that current output will accrue to families as income in proportion to the amounts of labor, measured in efficiency units, that they supply. 
Assumption 4. Output is proportional to inputs of labor measured in efficiency units.

A natural normalization is that an adult who possesses human capital in the amount $\lambda_{t}$ is endowed with $\lambda_{t}$ efficiency units of labor, which he or she supplies completely inelastically. Let a child supply $\left(1-e_{t}\right) \gamma$ efficiency units of labor when the child works $1-e_{t}$ units of time, where $\gamma \in(0,1)$, i.e., a full-time working child is less productive than an uneducated adult. A family with $n_{t}$ children therefore has a total income in state $s_{t}$ of

$$
y_{t}\left(s_{t}\right)=\alpha\left[\Lambda_{t}\left(s_{t}\right)+n_{t}\left(1-e_{t}\right) \gamma\right], \quad s_{t}=1,2,3
$$

where the scalar $\alpha(>0)$ denotes the productivity of human capital, measured in units of output per efficiency unit of labor input.

\subsection{Disease and the Epidemiological Environment}

The biology of HIV and AIDS is well known. HIV spreads through sexual intercourse or contact with infected blood, be it through unsterilized needles, other medical instruments or transfusion. Epidemiological and demographic modelling has proven to be difficult because behaviour is heterogeneous across subpopulations. However, a series of models of the spread of HIV have been formulated and successfully applied to particular countries (see, e.g., Magruder, 2005, and Mulder and Johnson, 2005, for surveys and discussion). Such models typically break down the population into groups with respect to gender, family status, sexual activity and class, predict infectivity at the micro level and then derive the consequences at the aggregate level.

We incorporate two key characteristics of such models into our macroeconomic model. First, the current risk of infection is an increasing function of the number of people infected in the past. Second, prevalence rates depend on the time that has passed since the outbreak of the disease. ${ }^{1}$ In what follows, we shall need an aggregate statistic of premature adult mortality. The proportion of all young adults at the start of period $t$ who will live to see old age is

\footnotetext{
${ }^{1}$ Random shocks to the level of mortality can also be incorporated.
} 
$\left(2 \pi_{t}(1)+\pi_{t}(2)+\pi_{t}(3)\right) / 2$. We therefore define the adult survival rate as

$$
\kappa_{t} \equiv\left[1+\pi_{t}(1)-\pi_{t}(4)\right] / 2 \leq 1
$$

where $\kappa_{t}=1$ if there is no premature mortality at all $\left(\pi_{t}(1)=1\right)$, and $\kappa_{t}<1$ otherwise; so that $1-\kappa_{t}$ is the level of premature adult mortality in period $t$. Epidemiological modelling then implies the following aggregate relationship:

$$
\kappa_{t+1}=g\left(\kappa_{t}, t\right)
$$

where the epidemic starts at $t=0$ in an environment with some pre-existing level of mortality $1-\kappa_{-1} \leq 1$ and $g$ is a function $[0,1] \times \mathbb{N} \rightarrow[0,1]$. The known patterns of how the pandemic evolves suggest that there exists a point in time $T$ such that the function $g$ satisfies the following conditions:

$$
\kappa_{t+1}=g\left(\kappa_{t}, t\right)\left\{\begin{array}{l}
<\kappa_{t} \quad \forall t \in[0, T) \\
\geq \underline{\kappa} \equiv g\left(\kappa_{T}, T\right) \quad \forall t \geq T
\end{array}\right.
$$

The pandemic reaches peak mortality in period $T$. Thereafter, it may wane a little or decline substantially.

\subsection{The Household's Behavior}

It is assumed that all allocative decisions lie in the parents' hands, as long as they are alive. We rule out any bequests at death, so that the whole of current income, as given by (4), is consumed. Where the allocation of consumption within the family is concerned, let the husband and wife enjoy equality as partners, and let each child obtain a fraction $\beta \in(0,1)$ of an adult's consumption if at least one adult survives. Full orphans $\left(s_{t}=4\right)$ do not attend school and consume what they produce as child laborers - unless adequate social arrangements are in place to care for them.

Consider a union of partners with human capital $\lambda_{t}$. The household's budget constraint is

$$
\left[\left(3-s_{t}\right)+n_{t} \beta\right] c_{t}+\alpha n_{t} \gamma e_{t} \leq \alpha\left[\left(3-s_{t}\right) \lambda_{t}+n_{t} \gamma\right], \quad s_{t}=1,2
$$


where $c_{t}$ is the level of each adult's consumption. The LHS is the sum of consumption and the opportunity costs of the children's schooling. The expression on the RHS is the family's so-called full income. ${ }^{2}$ Observe that single-parent households not only have lower levels of full income than their otherwise identical two-parent counterparts, but also face a higher relative price of education, defined as $\alpha n_{t} \gamma /\left[\left(3-s_{t}\right)+n_{t} \beta\right]$.

Let all mortality among children occur in infancy, and suppose that so-called 'replacement fertility' behavior is unhindered by premature adult mortality.

Assumption 5. Couples have children while they are young until some exogenously fixed number have survived infancy, a target that may vary from period to period.

The assumption that net fertility is unaffected by changes in mortality due to disease requires justification. Theory suggests that high mortality among adults may lead to a high precautionary demand for children at the expense of their education. Using data on a panel of countries, both Lorentzen et al. (2005) and Kalemli-Ozcan (2006) find that adult mortality and gross fertility (the total fertility rate) are indeed positively related - in contrast to Young's (2005) finding for South Africa. Here it should be remarked that AIDS is also causing a heavy toll of child mortality through transmission at birth, so that a rise in gross fertility, should it occur, will not be matched by a corresponding rise in net fertility. Most epidemiological models suggest that as mortality rates increase, fertility rates tend to fall, though the decline is modest (see, e.g., Mulder and Johnson [2005]). On balance, Assumption 5 seems to be a justifiable simplification. In our framework, moreover, lower fertility introduces opposing effects on the optimal level of education, as both the weight on future utility from investment in education and the sacrifice of current consumption become smaller when net fertility declines. ${ }^{3}$ In the present setting, therefore, the assumption that net fertility is given in each generation errs, if at all, on the side of caution. Finally, our qualitative results concerning the threat of an economic collapse remain valid even if education were to increase when fertility declines. ${ }^{4}$

\footnotetext{
${ }^{2} \mathrm{~A}$ household's full income is the scalar product of its endowment vector and the vector of market prices. Here, output is taken as the numéraire.

${ }^{3}$ In the numerical example in Section 4, education actually declines slightly when fertility declines.

${ }^{4}$ Bruhns (2005) formulates a closely related theoretical model in which households choose net fertility, and
} 
With $n_{t}$ thus fixed, the adults wait until the state of the family becomes known, and the survivor(s) then choose some feasible pair $\left(c_{t}, e_{t}\right)$ subject to (8). They are assumed to have preferences over their own current consumption and the human capital attained by their children in adulthood, taking into account the fact that an investment in a child's education will be wholly wasted if that child dies prematurely in adulthood. Let mothers and fathers have identical preferences, and for two-parent households, let there be no 'joint' aspect to the consumption of the bundle $\left(c_{t}, e_{t}\right)$ : each surviving adult derives (expected) utility from the bundle so chosen, and these utilities are then added up within the family. In effect, whereas $c_{t}$ is a private good, the human capital of the children in adulthood is a public good within the marriage. Since all the children attain $\lambda_{t+1}$, the only form of uncertainty is that surrounding the number who will not die prematurely as adults, which is denoted by the random variable $a_{t+1}$. Let preferences be separable, with representation

$$
E U_{t}\left(s_{t}\right)=\left(3-s_{t}\right)\left[u\left(c_{t}\right)+\left(E_{t} a_{t+1}\right) \cdot v\left(\lambda_{t+1}\right)\right], \quad s_{t}=1,2
$$

where the contribution $v\left(\lambda_{t+1}\right)$ counts only when death does not come early, $E$ is the expectation operator and $E_{t} a_{t+1}$ is the expected number of children surviving into old age, where the expectation is formed at time $t$. The sub-utility functions $u(\cdot)$ and $v(\cdot)$ are assumed to be increasing, continuous and twice-differentiable. Denoting by $\kappa_{t+1}^{e}$ the parents' subjective probability that a child born in period $t$ who grows to adulthood will survive to old age, and recalling Assumption 1 and that all children are treated identically, we obtain

$$
\left(E_{t} a_{t+1}\right) \cdot v\left(\lambda_{t+1}\right)=n_{t} \kappa_{t+1}^{e} v\left(\lambda_{t+1}\right)
$$

where $\lambda_{t+1}$ is given by (3). A reduction in $\kappa_{t+1}^{e}$ therefore effectively entails a weaker taste for the children's education. It will be convenient in what follows to rewrite (9) as

$$
E U_{t}\left(s_{t}\right)=\left(3-s_{t}\right)\left[u\left(c_{t}\right)+n_{t} \kappa_{t+1}^{e} \cdot v\left(z\left(s_{t}\right) f\left(e_{t}\right) \Lambda_{t}\left(s_{t}\right)+1\right)\right], \quad s_{t}=1,2
$$

since both types of single-parent families are identical. Hence, it suffices to examine the states $s_{t}=1,2$. A family in state $s_{t}(=1,2)$ in period $t$ solves the following problem:

$$
\max _{\left(c_{t}, e_{t}\right)} E U_{t}\left(s_{t}\right) \quad \text { s.t. }(8), c_{t} \geq 0, e_{t} \in[0,1]
$$

applies it to Kenya. She finds that endogenous changes in fertility have only minor effects on growth in the presence of the AIDS epidemic. 
Let $\left[c_{t}^{0}\left(\Lambda_{t}\left(s_{t}\right), s_{t}, \kappa_{t+1}^{e}\right), e_{t}^{0}\left(\Lambda_{t}\left(s_{t}\right), s_{t}, \kappa_{t+1}^{e}\right)\right]$ solve problem (11), whose parameters are $\left(\alpha, \beta, \gamma, n_{t}\right)$. Since current consumption is maximized by choosing $e_{t}=0$, it follows that the parents' altruism towards their children must be sufficiently strong if they are to choose $e_{t}>0$.

Assumption 6. Both goods are non-inferior. ${ }^{5}$

It follows at once that:

$$
\frac{\partial e_{t}^{0}\left(\Lambda_{t}\left(s_{t}\right), s_{t}, \kappa_{t+1}^{e}\right)}{\partial \Lambda_{t}\left(s_{t}\right)} \geq 0 \quad \text { and } \quad \frac{\partial c_{t}^{0}\left(\Lambda_{t}\left(s_{t}\right), s_{t}, \kappa_{t+1}^{e}\right)}{\partial \Lambda_{t}\left(s_{t}\right)} \geq 0 .
$$

Inspection of (10) reveals that an increase in $\kappa_{t+1}^{e}$ induces an increase in $e_{t}^{0}\left(\Lambda_{t}\left(s_{t}\right), s_{t}, \kappa_{t+1}^{e}\right)$ if $0<e_{t}^{0}\left(\Lambda_{t}\left(s_{t}\right), s_{t}, \kappa_{t+1}^{e}\right)<1$ and preserves $e_{t}^{0}\left(\Lambda_{t}\left(s_{t}\right), s_{t}, \kappa_{t+1}^{e}\right)=1$; for it increases the weight on $v\left(\lambda_{t+1}\right)$ relative to that on $u\left(c_{t}\right)$. An increase in $\kappa_{t+1}^{e}$ therefore has the opposite effect on $c_{t}^{0}\left(\Lambda_{t}\left(s_{t}\right), s_{t}, \kappa_{t+1}^{e}\right)$.

The remaining comparative static results concern the effect of family status in the present on investment in, and the accumulation of, human capital. Note that, independently of Assumption 1, the upper boundaries of the budget sets in the cases $s_{t}=2$ and $s_{t}=3$ lie strictly inside that associated with $s_{t}=1$ and that the price of $c_{t}$ relative to $e_{t}$ is lower for $s_{t}=2,3$ than for $s_{t}=1$. We then obtain $e_{t}^{0}\left(\Lambda_{t}(1), 1, \kappa_{t+1}^{e}\right) \geq e_{t}^{0}\left(\Lambda_{t}(2), 2, \kappa_{t+1}^{e}\right)=e_{t}^{0}\left(\Lambda_{t}(3), 3, \kappa_{t+1}^{e}\right)$ and $\lambda_{t+1}(1) \geq \lambda_{t+1}(2)=\lambda_{t+1}(3)$.

We now introduce the important assumption that altruism is not operative when the adults are uneducated, i.e., the adults are so poor that they use all their resources for consumption.

Assumption 7. $e_{t}^{0}\left(\Lambda_{t}(1), 1, \kappa_{t+1}^{e}\right)=0 \forall \kappa_{t+1}^{e} \in[\underline{\kappa}, 1]$ and $\forall \Lambda_{t}(1) \leq 2+\Delta$ for some $\Delta>0$.

It follows at once that $e_{t}^{0}\left(\Lambda_{t}(2), 2, \kappa_{t+1}^{e}\right)=e_{t}^{0}\left(\Lambda_{t}(3), 3, \kappa_{t+1}^{e}\right)=0 \quad \forall \kappa_{t+1}^{e} \in[\underline{\kappa}, 1]$ and $\forall \Lambda_{t}(2)=\Lambda_{t}(3) \leq 1+\Delta / 2$. Assumption 7 is a necessary, but not a sufficient condition for the existence of a poverty trap. It can be shown that under Assumption 7 and in the absence of premature adult mortality, the system has at least two stationary states if $z(1) f(1) 2 \lambda^{a}+1 \geq$

\footnotetext{
${ }^{5}$ Note that $\Lambda_{t}$ enters into both the budget constraint and the utility that adults derive from $\lambda_{t+1}$. The definition of inferior goods in this particular set-up is not, therefore, the same as the textbook version.
} 
$\lambda^{a}$, where $\lambda^{a}$ is the lowest level of an adult's human capital such that a two-parent household chooses full education for the children in such an environment (Bell and Gersbach, 2001).

\subsection{Dynamics}

The structure built up thus far is a random dynamical system, which can be compactly described as follows. Recalling that $e_{t}^{0}\left(\Lambda_{t}\left(s_{t}\right), s_{t}, \kappa_{t+1}^{e}\right)$ is chosen so as to solve problem (11), eq. (2) may be written

$$
\lambda_{t+1}= \begin{cases}z\left(s_{t}\right) \cdot f\left(e_{t}^{0}\left(\Lambda_{t}\left(s_{t}\right), s_{t}, \kappa_{t+1}^{e}\right)\right) \Lambda_{t}\left(s_{t}\right)+1, & s_{t}=1,2 \\ 1 & s_{t}=4\end{cases}
$$

This component is random in the sense that although each child attains $\lambda_{t+1}$ in adulthood with certainty, he or she can wind up in any of the states $s_{t+1} \in\{1,2,3,4\}$ after reaching adulthood and forming a family. The other components of the system are eq. (6) and individuals' formation of expectations about future mortality, that is, how they arrive at $\kappa_{t+1}^{e}$.

Inspection of (12) in the light of Assumption 1 reveals that given the household's preferences and the production and education technologies, the level of human capital attained by an individual who reaches adulthood in period $t+1$ depends only on two 'histories' and the level of human capital of the individual's ancestral forebears in period $0, \lambda_{0}$. The histories in question are: (i) the particular sequence of family states running from period 0 to period $t$, which is denoted by $\sigma^{t} \in S_{0} \times S_{1} \times \ldots \times S_{t} \equiv S^{t}$; and (ii) the sequence of (subjective) expectations about premature adult mortality of one generation hence, $\left\{\kappa_{k+1}^{e}\right\}_{k=0}^{t}$. Formally,

$$
\lambda_{t+1}\left(\sigma^{t}\right)=\lambda_{t+1}\left(\sigma^{t} \in S^{t},\left\{\kappa_{k+1}^{e}\right\}_{k=0}^{t}, \lambda_{0} ; \cdot\right), \quad \forall \sigma^{t} \in S^{t} .
$$

The distribution of individual human capital levels in period $t+1$ depends on the actual history of mortality up to the start of that period, namely, $\left\{\kappa_{k}\right\}_{k=0}^{t}$. 


\section{Premature Mortality, Inequality and Economic Collapse}

How a full-blown epidemic affects the system as a whole depends, in general, on the initial conditions. Premature adult mortality is a fact of life, epidemic or no epidemic, and however small its level may be, it will create full orphans and bereaved spouses. In the absence of suitable social and insurance arrangements to support them, inequality will surely follow.

In order to make the analysis tractable, we make the following assumptions, which ensure that the system is initially homogeneous in certain key respects. First, parents are perfect substitutes: $2 z(1)=z(2)=z(3)$. Second, levels of human capital and productivity before the outbreak are such that all children, including full orphans, enjoyed full-time education. ${ }^{6}$ It follows that at the time of the outbreak $(t=0)$, all adults have the same level of human capital, and the entire economy is on a path with the asymptotic growth rate $2 z(1) f(1)-1$, which is assumed to be positive.

The outbreak affects the system's subsequent development in two ways. First, children who are left as unsupported orphans $\left(s_{0}=4\right)$ will fall at once into the poverty trap. Assumption 7 also implies that $e_{t}^{0}\left(2,1, \kappa_{t+1}^{e}\right)=0 \forall t$ and $\forall \kappa_{t+1}^{e} \in[\underline{\kappa}, 1]$ : even if both parents survive but have experienced such a childhood, they cannot afford to send their children to school. In the absence of support, therefore, all orphans fall into the poverty trap, and their succeeding lineage will remain there. If $\pi_{0}(4)$ is large enough to cause a breakdown in the existing arrangements for caring for full orphans, the consequences will be very damaging.

Second, even when at least one parent survives, the sudden increase in premature adult mortality may reduce the expected returns to investment in education so sharply as to reduce $e_{0}^{0}\left(\Lambda_{0}\left(s_{0}\right), s_{0}, \kappa_{1}^{e}\right) \quad\left(s_{0}=1,2,3\right)$, depending on how such expectations are formed and the level of $\lambda_{0}$. This effect will normally be strengthened by the attendant increase in the proportion of one-parent families in period 0 ; for, given $\lambda_{0}$ and $\kappa_{1}^{e}, e_{0}^{0}\left(\Lambda_{0}(1), 1, \kappa_{1}^{e}\right) \geq$ $e_{0}^{0}\left(\Lambda_{0}(2), 2, \kappa_{1}^{e}\right)=e_{0}^{0}\left(\Lambda_{0}(3), 3, \kappa_{1}^{e}\right)$. The next step, therefore, is to establish how large the

\footnotetext{
${ }^{6} \mathrm{How}$ full orphans are cared for is not specified in this section. Their numbers are assumed to be sufficiently small that the burden of caring for them up to the outbreak was a light one.
} 
shock to mortality must be in order that these children and their offspring slide into the poverty trap.

\subsection{Stationary States}

We introduce the critical value function $\lambda^{*}(s, \kappa)$ for $s \in\{1,2\}$, which is defined for stationary fertility, $n_{t}=n_{t+1}=n \forall t$, and stationary mortality, $\kappa_{t}=\kappa_{t+1}=\kappa \forall t$. In this stationary setting, it is natural to assume perfect foresight: $\kappa_{t+1}^{e}=\kappa_{t+1}=\kappa \forall t \geq 0$. The critical value function is then given by:

$$
\lambda^{*}(s, \kappa)=z(s) f\left(e^{0}\left(\Lambda^{*}(s), s, \kappa\right)\right) \Lambda^{*}(s)+1,
$$

where $\Lambda^{*}(1)=2 \lambda^{*}(1), \Lambda^{*}(2)=\Lambda^{*}(3)=\lambda^{*}(2)=\lambda^{*}(3) . \lambda^{*}(s, \kappa)$ is the critical level of human capital associated with a particular family state $s$, that is, in any pair of generations, parent(s) and offspring share the same state and the same, stationary level of human capital.

It is clear from Assumption 7 that $\lambda^{*}(s, \kappa)=1$ solves (14). The assumption that $2 z(1) f(1) \geq$ 1 also ensures, however, that there is also at least one solution that exceeds unity if $\kappa$ is not too small. ${ }^{7}$ Let $\lambda^{*}(s, \kappa)$ denote the smallest of the values that exceed unity.

\section{Lemma 1}

(i) $\quad \partial \lambda^{*}(s, \kappa) / \partial \kappa<0, \quad s=1,2$

(ii) $\quad \lambda^{*}(1, \kappa) \leq \lambda^{*}(2, \kappa)=\lambda^{*}(3, \kappa)$

Proof: see appendix. Part (i) states that an increase in premature adult mortality may cause a group that was earlier enjoying self-sustained growth to fall into the poverty trap. Part (ii) states that single-parent families need individual levels of human capital that are at least as large as those needed by two-parent ones in order to escape the trap. It follows that an increase in premature adult mortality may also increase the share of all families falling into the trap by increasing the proportion of one-parent families.

\footnotetext{
${ }^{7}$ This claim follows by continuity from the associated proposition in Bell and Gersbach (2001), in which there is no premature adult mortality.
} 
Lemma 1 enables us to say something definite about the evolution of human capital. If a family is in state $s$, we have the following relationship between the adults' human capital and that attained by their children in adulthood when the shock at $t$ represented by $\kappa_{t-1}-\kappa$ is permanent, that is, when the survival rate is constant at $\kappa$ from $t$ onwards:

$$
\lambda_{t+1} \gtreqless \lambda_{t} \quad \text { according as } \quad \lambda_{t} \gtreqless \lambda^{*}(s, \kappa) \text {. }
$$

Hence, if human capital does start to decrease under these conditions, it will eventually reach $\lambda=1,{ }^{8}$ which is a stable stationary state.

\subsection{Dynamics}

The critical value function plays an essential role in the analysis of the long-term behaviour of the system. Only under a very restrictive assumption, however, does it suffice to establish whether a particular group or a whole society will slide into the poverty trap, namely, that the shock to mortality is permanent. In fact, epidemics tend to burn themselves out, and after enough time has elapsed, general mortality tends to revert to some 'normal' level. Given the nature of HIV/AIDS and our choice of an OLG framework, in which each period is a generation, it seems defensible to describe the course of a full-blown epidemic as follows.

Assumption 8. The outbreak occurs at the start of period 0 and runs its course through to the end of period 1, with $\kappa_{-1}>\max \left(\kappa_{0}, \kappa_{1}\right)$. From period 2 onwards, $\kappa_{-1}$ rules once more.

Where expectations are concerned, we assume that the outbreak is a surprise, but that there is perfect foresight thereafter.

Assumption 9. The outbreak is not anticipated before period 0, but immediately after the outbreak, all agents foresee the sequence $\left\{\kappa_{t}\right\}_{t=0}^{\infty}$ perfectly.

Observe that the size of the initial shock to mortality, $\kappa_{-1}-\kappa_{0}$, affects the proportions of

\footnotetext{
${ }^{8}$ Strictly speaking, this statement holds when the system starts with $s_{t}=1$, or if $s_{t}=2,3$ and the system remains in those states for some time.
} 
families falling into the various states $\left(s_{0}=1,2,3,4\right)$, but not their choices of $e_{0}$ given their state. These choices are, however, influenced by the survival rate in period 1 , which, by assumption, is foreseen perfectly.

We do not specify for the moment how the arrangements for supporting full orphans are financed; but we do assume that the most vulnerable group in each period, namely, oneparent families with the lowest levels of human capital, is not burdened thereby and that no other group is so burdened that its offspring do worse than those whose parents make up the most vulnerable. This assumption will be innocuous if $\kappa_{-1}$ is close to one and the shock is not too large. ${ }^{9}$

In view of Lemma 1, it suffices to follow the fortunes of children who are raised in singleparent families in period 0 , and then those of their children who are raised in the same circumstances in period 1 and attain adulthood in period 2. By virtue of Assumptions 1 and 2, one need examine only the sequence $\sigma^{1}=(2,2)$. Noting that it is only the level of mortality in the next period that affects the choice of $e_{t}$, we have the following sub-sequence for such a lineage:

$$
\lambda_{1}(2)=z(2) f\left(e_{0}^{0}\left(\lambda_{0}, 2, \kappa_{1}\right)\right) \lambda_{0}+1
$$

and

$$
\lambda_{2}(2,2)=z(2) f\left(e_{1}^{0}\left(\lambda_{1}(2),(2,2), \kappa_{-1}\right)\right) \lambda_{1}(2)+1 .
$$

Thus, $\lambda_{2}(2,2) \equiv \lambda_{2}\left((2,2), \kappa_{-1}, \kappa_{1}, \lambda_{0}\right)$ is independent of $\kappa_{0}$. Since these adults have the lowest levels of human capital in period 2, it follows at once that no intervention beyond ensuring the care of all orphans is needed in order to prevent any group sliding into the trap if the following condition holds:

$$
\lambda_{2}\left((2,2), \kappa_{-1}, \kappa_{1}, \lambda_{0}\right)>\Lambda^{*}\left(2, \kappa_{-1}\right) .
$$

Remark 1. The size of the shock to mortality in period $0, \kappa_{-1}-\kappa_{0}$, affects the proportions of (nuclear) families falling into the various states $\left(s_{0}=1,2,3,4\right)$, but not their choices of $e_{0}$ given their state. Hence, under the above assumptions about the unspecified mechanism for financing the care of full orphans, it is only the size of the shock in the second period relative

\footnotetext{
${ }^{9}$ We postpone a rigorous treatment of the general case to some later date.
} 
to the status quo ante, $\kappa_{-1}-\kappa_{1}$, that matters in determining whether a collapse will ensue. Remark 2. In view of $\kappa_{-1}>\max \left(\kappa_{0}, \kappa_{1}\right)$ (recall Assumption 8), it follows at once that condition (17) cannot hold if $\lambda_{0}=\Lambda^{*}\left(2, \kappa_{-1}\right)$ and $e_{0}^{0}\left(\left(\Lambda^{*}\left(2, \kappa_{-1}\right), 2, \kappa_{-1}\right)<1\right.$. A margin of safety over $\Lambda^{*}\left(2, \kappa_{-1}\right)$ must exist at the outset.

We now examine what happens when the arrangements for raising orphans break down at once and condition (17) does not necessarily hold. Denote by $P_{t}$ the fraction of the population of adults whose human capital is at most unity in period $t$, and by $R_{t}$ the fraction of individuals that possess at least $\lambda^{*}\left(2, \kappa_{-1}\right)$. Note that $P_{t}+R_{t} \leq 1$. Recalling (15) and (16), we obtain the following results for the short run:

\section{Lemma 2}

Suppose that orphans are uncared for. Then the proportions $P_{1}$ and $R_{1}$ satisfy the following:

(i) if $\lambda_{1}\left(2, \kappa_{1}, \lambda_{0}\right) \geq \lambda^{*}\left(2, \kappa_{-1}\right)$, then $P_{1}=\pi_{0}(4), R_{1}=1-\pi_{0}(4)$;

(ii) if $\lambda_{1}\left(1, \kappa_{1}, \lambda_{0}\right)>\lambda^{*}\left(2, \kappa_{-1}\right)>\lambda_{1}\left(2, \kappa_{1}, \lambda_{0}\right)$, then $P_{1} \geq \pi_{0}(4), R_{1}=\pi_{0}(1)$;

(iii) if $\lambda^{*}\left(1, \kappa_{-1}\right)>\lambda_{1}\left(1, \kappa_{1}, \lambda_{0}\right)$, then $P_{1} \geq \pi_{0}(4), R_{1}=0$.

The three claims follow immediately from the preceding discussion. In case (i), families with at least one surviving adult will stay out of the trap, at least temporarily, although one-parent households will henceforth experience growth at a lower rate if $e_{0}^{0}(2)<1$. The resulting inequality among families with adults will be propagated into the future, with further differentiation arising from future differences in $e_{t}^{0}(\cdot)$ among them. In case (ii), only families with two adults will avoid the trap. Thereafter, the pattern of progressive differentiation described in case (i) will also take hold here. In case (iii), all families begin to descend into the trap immediately.

We proceed to period 2. If condition (17) is violated, then $R_{2} \leq \pi_{0}(1) \cdot \pi_{1}(1)$, with equality if and only if $\lambda_{2}\left((1,1), \kappa_{-1}, \kappa_{1}, \lambda_{0}\right) \geq \lambda^{*}\left(1, \kappa_{-1}\right)$. On the further assumption that the sequence $\left\{\kappa_{0}, \kappa_{1}, \kappa_{t}=\kappa_{-1} \forall t \geq 2\right\}$ generates an intolerable burden for two-parent familes to keep the 
needy out of the trap, and so results in a breakdown of the earlier arrangements for supporting them, the preceding discussion yields straightforward implications for the system's long-run dynamics.

\section{Proposition 1}

If condition (17) is violated and $\kappa_{t}<1$ for all $t \geq 0$, then:

(i) $P_{t} \geq P_{t-1}+\left(1-\kappa_{t-1}\right)^{2}\left(1-P_{t-1}\right), \quad t \geq 1$

(ii) $\lim _{t \rightarrow \infty} P_{t}=1$

The share of uneducated families grows over time until, in the limit, the whole population is in backwardness. Not only do some adults suffer sickness and early death, but the whole society descends progressively into the poverty trap. This dramatic implication leads one to ask what social arrangements can be made to deal with this danger. One answer is to pool the risks, a possibility which we take up in Section 5.

\subsection{Inequality}

The preceding argument establishes that the outbreak of an epidemic of the AIDS kind at first generates inequality if the society is initially homogeneous and the arrangements for supporting the needy break down as a result of the shock. A long-drawn out epidemic that maintains substantial levels of premature adult mortality will, however, eventually do away with inequality; for in the limit, all members of the society will find themselves in the poverty trap. The simple point here is that concerns about inequality in the face of such an epidemic must be formulated with caution. Permanent poverty for all is hardly attractive when sustainable growth for all - albeit marred by temporary inequality - is a feasible alternative. 


\section{An Example}

This section provides a detailed analysis of an example when Assumptions 1, 4, 5, 8 and 9 are assumed to hold in order to illustrate the most important results from the household model and how the steady state associated with a particular household state $s_{t}=(1,2)$ depends on preferences, premature mortality, and the production and educational technologies.

\subsection{The Household's Decisions}

We work with the following functional forms:

$$
\begin{aligned}
f\left(e_{t}\right) & =e_{t} \\
u\left(c_{t}\right) & = \begin{cases}c_{t} & \text { if } \quad c_{t} \geq c^{\text {min }} \\
-\infty & \text { otherwise }\end{cases} \\
v\left(\lambda_{t+1}\right) & =\delta \ln \left(\lambda_{t+1}+\zeta\right), \text { with } 0<\delta<1 \text { and } \zeta>-1
\end{aligned}
$$

To simplify the analysis, we maintain the assumption that $z(1)=z(2) / 2 \equiv \bar{z}$. Note that this assumption and the functional forms imply that Assumptions 2 and 3 hold. We summarize the properties of the household's optimal choices in the following proposition.

\section{Proposition 2}

(i) $e_{t}^{0}\left(\Lambda_{t}(1), 1, \kappa_{t+1}\right) \geq e_{t}^{0}\left(\Lambda_{t}(2), 2, \kappa_{t+1}\right) \quad \forall \lambda_{t}$ and $\forall \kappa_{t+1} \in[\underline{\kappa}, 1]$.

(ii) $e^{0}\left(s_{t}\right):=\lim _{\lambda_{t} \rightarrow \infty} e_{t}^{0}\left(\Lambda_{t}\left(s_{t}\right), s_{t}, \kappa_{t+1}\right)=\min \left\{\frac{\delta \kappa \cdot\left(3-s_{t}+n \beta\right)}{\alpha \gamma}, 1\right\}$, where $\lim _{t \rightarrow \infty} \kappa_{t+1}=\kappa$ and $n_{t}=n \forall t$.

(iii) If $e^{0}(1)<1$, then $e^{0}(1)>e^{0}(2)$.

(iv) $\frac{\partial e_{t}^{0}\left(\Lambda_{t}\left(s_{t}\right), s_{t}, \kappa_{t+1}\right)}{\partial \Lambda_{t}\left(s_{t}\right)}>0 \quad \forall e_{t}^{0}\left(\Lambda_{t}\left(s_{t}\right), s_{t}, \kappa_{t+1}\right) \in(0,1)$.

(v) $\frac{\partial c_{t}^{0}\left(\Lambda_{t}\left(s_{t}\right), s_{t}, \kappa_{t+1}\right)}{\partial \Lambda_{t}\left(s_{t}\right)}>0 \quad \forall \lambda_{t}>\hat{\lambda} \equiv \sqrt{\frac{\gamma(1+\zeta) n_{t}}{2 \bar{z}\left(3-s_{t}\right)}}$. 
Proof: see the appendix, in which the closed-form solutions for $c_{t}^{0}\left(\Lambda_{t}\left(s_{t}\right), s_{t}, \kappa_{t+1}\right)$ and $e_{t}^{0}\left(\Lambda_{t}\left(s_{t}\right), s_{t}, \kappa_{t+1}\right)$ are derived. As long as $\lambda_{t}>\hat{\lambda}$, the example fulfills all the conditions of the general household model, as set out in Section 2.2.

\subsection{Critical values of $\lambda$}

The critical value $\lambda^{*}(s, \kappa)$ is given by (14) and the expression for $e_{t}^{0}\left(\Lambda_{t}\left(s_{t}\right), s_{t}, \kappa_{t+1}\right)$ derived in the appendix:

$$
\lambda^{*}\left(s_{t}, \kappa\right)=\bar{z} \frac{\left(3-s_{t}+n \beta\right) 2 \kappa \delta \bar{z} \cdot \lambda^{*}-\alpha \gamma(1+\zeta)}{2 \alpha \gamma \bar{z} \cdot \lambda^{*}} \cdot 2 \lambda^{*}+1, \quad s_{t}=1,2
$$

Solving for $\lambda^{*}(\cdot)$ yields:

\section{Corollary 1}

Suppose $\zeta>0$ and $\alpha \gamma \zeta>\left(3-s_{t}+n \beta\right) 2 \delta \kappa \bar{z}-\alpha \gamma>0$. Then for $s_{t}=1,2$, there exists a unique stationary state $\lambda^{*}\left(s_{t}, \kappa\right)>1$ that is associated with a positive level of education:

$$
\lambda^{*}\left(s_{t}, \kappa\right)=\frac{\alpha \gamma \zeta}{\left(3-s_{t}+n \beta\right) 2 \delta \kappa \bar{z}-\alpha \gamma} .
$$

Note that $\partial \lambda^{*} / \partial \kappa<0$ : lower premature mortality among adults results in a lower value of $\lambda^{*}$. Thus, the critical stationary state has the following properties, which accord with intuition:

\section{Corollary 2}

Suppose $\zeta>0$ and $\alpha \gamma \zeta>\left(3-s_{t}+n \beta\right) 2 \delta \kappa \bar{z}-\alpha \gamma>0$. Then,
(i) $\frac{\partial \lambda^{*}\left(s_{t}, \kappa\right)}{\partial \kappa}<0$;
(ii) $\lambda^{*}(2, \kappa)>\lambda^{*}(1, \kappa)$;

(iii) there exists a $\hat{\kappa} \in(0,1)$ such that $\lim _{\kappa \rightarrow \hat{\kappa}} \lambda^{*}\left(s_{t}, \hat{\kappa}\right)=\infty$. 


\section{Pooling}

The prevailing form of social organization has a potentially important influence on how the economic system copes with premature adult mortality. We distinguish between two ideal, extreme types. First, there is the nuclear family, which is the basis of the preceding set-up. Parents are solely responsible for their own children, so that the children's fortunes depend entirely on their natural parents' health status and human capital (or income).

The second type involves collective arrangements, under which a subset of society, be it the inhabitants of a region or city, the members of a tribe, or even a very large extended family, pools its resources. It is widely observed that in Africa, orphans are often taken in by, and rotated among, relatives. To examine this arrangement, we allow the society to be pooled completely, that is, all surviving adults in the society take on joint responsibility for all children in their group. For simplicity, we assume that within each generation, all adults and children are treated identically - although this probably goes a bit too far: Case, Paxson and Ableidinger (2002), for example, show that the schooling of orphans heavily depends on how closely they are related to the adoptive household head. In any event, full pooling suffices to diversify completely the idiosyncratic mortality risk, and the pooled group faces only the aggregate risk, as summarized by $\kappa .{ }^{10}$ Pooling introduces the need for some additional notation: it will be denoted by the family state $s_{t}=0$. All the formal assumptions in preceding sections are maintained here.

\subsection{The Household's Behavior under Pooling}

By Assumption 5, each couple produces $n_{t}$ surviving children in period $t$; but not all of the adults themselves survive to rear their offspring. Under complete pooling, the children are

\footnotetext{
${ }^{10} \mathrm{We}$ could also consider partial pooling as an intermediate case where a sufficiently large subset of the society - subintervals in the model - is pooled. Partial pooling on such a scale already suffices to achieve complete insurance against idiosyncratic risks.
} 
effectively reared collectively, in the sense that each surviving 'pair' of adults raises

$$
n_{t}(0)=\frac{n_{t}}{\kappa_{t}}
$$

children. In effect, the burden of premature adult mortality is borne equally by all surviving members of a generation. The budget constraint of a representative 'pair' is

$$
\left[2+\left(n_{t} / \kappa_{t}\right) \beta\right] c_{t}+\alpha\left(n_{t} / \kappa_{t}\right) \gamma \cdot e_{t} \leq \alpha\left[2 \lambda_{t}+\left(n_{t} / \kappa_{t}\right) \gamma\right]
$$

a comparison of which with (8) reveals that, relative to an otherwise identical two-parent nuclear family, the presence of premature adult mortality implies a lower relative price of current consumption and a lower level of full income, measured in units of an adult's consumption, so long as $\beta>\gamma$. On this score, therefore, a rise in such mortality works to reduce education, relative to the two-parent, nuclear family. It is also seen that by setting $\kappa_{t}$ equal to 1 and $1 / 2$, respectively, (19) specializes to the cases $s_{t}=1$ and $s_{t}=2$ in (8). As will now be demonstrated, however, pooling is not necessarily an intermediate case between one- and two-parent nuclear families whenever $\kappa_{t} \in[1 / 2,1]$.

One can think of the pooling arrangement as a representative two-parent family looking after $n_{t} / \kappa_{t}$ children, as opposed to either one or two parents looking after $n_{t}$, as analyzed in Section 2. The transmission factor under pooling is therefore written as $z\left(0, \kappa_{t}\right)$. If there is no premature adult mortality, pooling is never called into operation, so that $z(0,1)=z(1)$. If $\kappa_{t}=1 / 2$, the question arises as to whether two parents can impart a higher potential to each of $2 n_{t}$ children than one parent (of either sex) to $n_{t}$; in keeping with Assumption 2, they could hardly do worse.

Assumption 10. For any given $n_{t}, z\left(0, \kappa_{t}\right)$ is a non-decreasing, continuous and differentiable function of $\kappa_{t}$; it also satisfies $z(0,1 / 2) \geq z(2) / 2$ and $z(0,1)=z(1)$.

Analogously to (2), the formation of human capital under pooling is given by

$$
\lambda_{t+1}=2 z\left(0, \kappa_{t}\right) f\left(e_{t}\right) \lambda_{t}+1
$$

Turning to preferences, let the 'couple' display the same degree of altruism towards natural and adopted children alike, which implies that all children will be treated in the same way. 
Analogously to (10), therefore,

$$
E U_{t}(0)=2\left[u\left(c_{t}\right)+n_{t}\left(\kappa_{t+1}^{e} / \kappa_{t}\right) \cdot v\left(2 z\left(0, \kappa_{t}\right) f\left(e_{t}\right) \lambda_{t}+1\right)\right]
$$

Since $\kappa_{t}<1$, a comparison of (21) and (10) reveals that there is a greater weight on the children's future human capital under pooling than under nuclear family arrangements (in which the weights are identical for one- and two-parent families). The assumption that the adults view all children in their care with equal altruism therefore tugs in the opposite direction to that of the price and income effects where investment in education is concerned.

Note that the optimal educational choice, denoted by $e_{t}^{P}\left(2 \lambda_{t}, \kappa_{t}, \frac{\kappa_{t+1}^{e}}{\kappa_{t}}\right)$, is a function of human capital and mortality in the present and the ratio of expected future to current mortality. Note that $e_{t}^{P}(\cdot, \cdot, \cdot)$ is increasing in the first two of its arguments when $e_{t}^{P} \in(0,1)$ if both goods are normal. Moreover, an increase of $\frac{\kappa_{t+1}^{e}}{\kappa_{t}}$ induces an increase in $e_{t}^{P}$ if $0<e_{t}^{P}<1$ and it preserves $e_{t}^{P}=1$; for it increases the weight on $v\left(\lambda_{t+1}\right)$ relative to that on $u\left(c_{t}\right)$. Note that Assumption 7 applied to the pooling case implies that in the case of a stationary environment with perfect foresight, i.e. $\kappa_{t+1}^{e}=\kappa_{t+1}=\kappa_{t}=\kappa, \quad \forall t$ and $n_{t+1}=n_{t}, \quad \forall t$, altruism is not operative when the adults are uneducated, i.e., $e_{t}^{P}\left(2 \lambda_{t}, \kappa, 1\right)=0 \forall \kappa \in[\underline{\kappa}, 1]$ and $\forall 2 \lambda_{t} \leq 2+\Delta, \Delta>0$. This follows from

$$
e_{t}^{P}\left(2 \lambda_{t}, \kappa, 1\right) \leq e_{t}^{P}\left(2 \lambda_{t}, 1,1\right)=e_{t}^{0}\left(\Lambda_{t}(1), 1,1\right)
$$

In the case of a stationary environment with perfect foresight, the critical value of human capital in the pooling case satisfies

$$
\lambda^{*}(0, \kappa)=2 z(0, \kappa) f\left(e^{P}\left(2 \lambda^{*}(0, \kappa), \kappa, 1\right)\right) \cdot \lambda^{*}(0, \kappa)+1
$$

Were it not for the force of equal altruism towards all children under pooling, Assumption 10 and the argument that yields $\lambda_{t+1}(1) \geq \lambda_{t+1}(2)=\lambda_{t+1}(3)$ in Section 2.2 would yield the following result: $\lambda^{*}(1, \kappa) \leq \lambda^{*}(0, \kappa) \leq \lambda^{*}(2, \kappa) \forall \kappa \in[1 / 2,1]$. An alternative assumption about altruism towards adopted children will suffice to ensure that it indeed holds. 


\section{Lemma 3}

Suppose, by social convention, that all children must be treated identically, but surviving adults value only the future human capital attained by their natural children. Then

$$
\lambda^{*}(1, \kappa) \leq \lambda^{*}(0, \kappa) \leq \lambda^{*}(2, \kappa) \quad \forall \kappa \in[1 / 2,1]
$$

\subsection{The Virtues and Drawbacks of Pooling}

Since pooling is a form of social insurance against premature mortality, it is interesting to ask whether this form of organization is better able to withstand a shock to mortality than one based on the nuclear family. To answer this question, we proceed as in Section 3.2. Since all state-sequences involve pooling, we abuse notation somewhat by setting $\sigma^{t}=0 \forall t$. We have, analogously to (15) and (16),

$$
\lambda_{1}(0)=2 z\left(0, \kappa_{0}\right) f\left(e^{P}\left(2 \lambda_{0}, \kappa_{0}, \kappa_{1} / \kappa_{0}\right)\right) \lambda_{0}+1
$$

and

$$
\lambda_{2}(0)=2 z\left(0, \kappa_{1}\right) f\left(e^{P}\left(2 \lambda_{1}(0), \kappa_{1}, \kappa_{-1} / \kappa_{1}\right)\right) \lambda_{1}(0)+1,
$$

and hence, by recursive substitution, the critical condition analogous to (17):

$$
\lambda_{2}\left(0, \kappa_{-1}, \kappa_{0}, \kappa_{1}, \lambda_{0}\right) \geq \lambda^{*}\left(0, \kappa_{-1}\right) .
$$

Observe that, in contrast to condition (17), $\kappa_{0}$ now plays a role; for it affects the budget set when the outbreak occurs in period 0 . The following result is immediate.

\section{Proposition 3}

Given Assumptions 8 and 9, no collapse will occur under pooling if condition (25) holds; otherwise, the entire group begins an immediate descent into the poverty trap.

The outcome in the first part stands in contrast to that in part (ii) of Proposition 1. Under pooling, moreover, perfect equality is maintained within each generation. The drawback arises when the course of mortality during the epidemic is adverse that the final level of 
human capital lies below the critical level in the final (also status quo ante) disease environment. Equality of treatment then pulls everyone down together, whereas in a nuclear family structure, two-parent families will continue to experience growth if $\lambda^{*}\left(1, \kappa_{-1}\right)<$ $\lambda_{2}\left((1,1), \kappa_{-1}, \kappa_{1}, \lambda_{0}\right)$, where it should be recalled from Lemma 3 that $\lambda^{*}\left(1, \kappa_{-1}\right) \leq \lambda^{*}\left(0, \kappa_{-1}\right)$. If $\lambda^{*}\left(1, \kappa_{-1}\right)<\lambda_{2}\left((1,1), \kappa_{-1}, \kappa_{1}, \lambda_{0}\right)$ indeed holds, there are very important consequences when policy interventions are possible; for two-parent families comprise the main tax base in a nuclear family setting.

If mortality does not revert to its status quo ante level, one can obtain definite qualitative results if the first maximum mortality attains after the outbreak is also the global one. As in Proposition 3, the possible outcomes involve two simple polar cases.

\section{Proposition 4}

Suppose condition (7) and Assumption 9 hold, with $\kappa_{0}<1$. Then, under pooling:

(i) if $\lambda^{*}\left(0, \kappa_{\tau}\right)>\lambda_{\tau}$ for some $\tau<T$ and $\kappa_{t}=\underline{\kappa} \forall t>T$, the economy will collapse;

(ii) if $\lambda_{T}>\lambda^{*}(0, \underline{\kappa})$ and $\kappa_{t+1} \geq \kappa_{t} \forall t>T$, the economy will not collapse.

Proof: see appendix. The proposition states that the epidemic poses a threat to the economy until mortality reaches its peak. If the economy can survive until period $T$, it will not then experience a collapse as long as mortality also declines thereafter. ${ }^{11}$

Finally, we establish a general collapse result for the pooling case that holds for any epidemiological pattern. For this purpose, we introduce the assumption that parents will fully educate their children if their human capital is sufficiently high.

Assumption 11. There exists $\lambda^{a}(\kappa)$ such that

$$
e^{P}\left(2 \lambda^{a}(\kappa), \kappa, \frac{\underline{\kappa}}{\kappa}\right)=1 \quad \forall \kappa \in[\underline{\kappa}, 1] .
$$

\footnotetext{
${ }^{11}$ Otherwise, a collapse after period $T$ cannot be excluded, even if $\kappa_{t}$ never falls below $\underline{\kappa}$ for $t>T$.
} 


\section{Proposition 5}

Suppose condition (7), Assumption 9 with $\kappa_{0}<1$ and Assumptions 10 and 11 hold. Then under pooling there exists a critical value $\lambda_{0}^{\text {crit }}$ such that the economy will collapse if and only if

$$
\lambda_{0}<\lambda_{0}^{c r i t}
$$

The proof is given in the appendix.

\section{Awareness Campaigns}

As established above, parents' expectations regarding the mortality risks facing their children in adulthood play an important role in influencing how the former react to the epidemic. Arguably, individuals will only adjust their expectations regarding the ensuing wave of mortality with a lag, so that Assumption 9 does not hold. While the disease is spreading, a slow adjustment of expectations is beneficial for long-run development, because families keep on investing in human capital. This may introduce some ethically troubling tradeoffs when a government or an international organization considers launching an awareness campaign. A proper understanding of the causes of the disease and its modes of transmission may help to reduce the current risk of infection, as individuals are induced to behave more cautiously, but it may also bring about an immediate upward revision of expectations about future mortality, since individuals also will become aware that the disease will not disappear soon.

To illustrate this potential tension, consider the following extreme case. Suppose $\kappa_{-1}=1$ and let the disease break out in period 0 with the epidemic pattern summarized by $\left\{g\left(\kappa_{t}, t\right)\right\}_{t=0}^{\infty}$. Up to some period $t^{\prime}$, individuals remain unaware of its long-term course and impact, and consider the attendant mortality as a temporary negative shock, i.e. each generation of parents forms the expectations $\kappa_{t+1}^{e}=1$ for all $t<t^{\prime}$. Now suppose that the launch of an awareness campaign at $t=0$ can so reduce the incidence of the disease in subsequent periods that the new epidemic pattern summarized by $\left\{\hat{g}\left(\hat{\kappa}_{t}, t\right)\right\}_{t=0}^{\infty}$ satisfies $\hat{g}\left(\hat{\kappa}_{t}, t\right)>g\left(\kappa_{t}, t\right) \forall t$. These 
efforts may also change expectations, however, as individuals become aware that their children will face similar risks. Suppose further that the campaign is so succesful that it leads to perfect foresight regarding the evolution of the epidemic. We obtain:

\section{Proposition 6}

The awareness campaign may trigger a collapse which otherwise would not occur.

Proof: see appendix. It should be emphasized that this proposition does not call awareness campaigns into question in a fundamental way. It does imply, however, that such campaigns - which can greatly reduce the number of deaths and those in dire need - should be complemented by policies that promise credibly to reduce future mortality risks, in order to avoid undesirable expectational feedbacks.

\section{Discussion and Conclusions}

The central conclusion of this paper is that the weakening of the mechanism through which human capital is transmitted and accumulated across generations through epidemic diseases becomes apparent only after a lag, and it is progressively cumulative in its effects. The purpose of this paper is the development of a suitable framework to examine the macroeconomic consequences of AIDS. The structure in this section can be directly used for policy analysis. When policy measures such as prevention and education can change the mortality pattern, the cost of such measures can be weighed against the benefits predicted by the model (see Bell, Devarajan and Gersbach, 2006, for an application to South Africa).

The current paper focusses on the feedbacks from premature mortality to education, the formation of human capital and output. The framework offers some useful directions for future research. Introducing physical capital would tend to weaken the link between the course of the epidemic and economic growth, as the depreciation of physical capital is not affected by the disease. In turn, the opportunity to accumulate physical capital diverts resources from human capital formation and may tend to aggravate the decline of education when a society 
is assailed by an epidemic. Whether the presence of physical capital tends to retard or to accelerate a collapse is an important avenue for further research. Moreover, there must be a concern about negative supply-side effects in the education sector. An epidemic disease such as AIDS may tend to reduce the supply of teachers in a higher proportion than children, which may undermine the quality of education and so accelerate a collapse. 


\section{Appendix}

\section{Proof of Lemma 1:}

In order to establish the relationship between $\lambda^{*}(s, \kappa)$ and $e^{0}\left(\Lambda^{*}(s), s, \kappa\right)$, we differentiate (14) totally and rearrange terms:

$$
\frac{d \lambda^{*}}{d \kappa}=\frac{(3-s) z(s) f^{\prime}\left(e^{0}\right) \frac{\partial e^{0}}{\partial \kappa}}{\frac{1}{\lambda^{*}}-(3-s) z(s) f^{\prime}\left(e^{0}\right) \frac{\partial e^{0}}{\partial \lambda^{*}}-\frac{1}{\lambda^{*}}(3-s) z(s) f\left(e^{0}\right)}
$$

Since $\lambda *(s, \kappa)$ is the smallest value that exceeds unity and since Assumption 7 holds, the slope of the right hand side of equation (14) is larger than 1 at $\lambda^{*}$. Hence,

$$
\frac{\partial}{\partial \lambda}\left((3-s) z(s) f\left(e^{0}\left(\Lambda^{*}(s), s, \kappa\right)\right) \lambda^{*}(s)\right)>1
$$

which implies

$$
(3-s) z(s) f^{\prime}\left(e^{0}\right) \frac{\partial e^{0}}{\partial \lambda^{*}}>\frac{1}{\lambda^{*}}\left\{1-(3-s) z(s) f\left(e^{0}\right)\right\}
$$

Hence, the denominator in (27) is negative. According to the properties of the function $e_{t}^{0}\left(\Lambda_{t}\left(s_{t}\right), s_{t}, \kappa_{t+1}^{e}\right)$, the numerator in (27) is positive, which proves the first claim. To establish the second claim, observe that

$$
\begin{aligned}
\lambda^{*}(1, \kappa) & =z(1) f\left(e^{0}\left(\Lambda^{*}(1), 1, \kappa\right) \cdot \Lambda^{*}(1, \kappa)+1\right. \\
& \geq z(2) f\left(e^{0}\left(\Lambda^{*}(1), 1, \kappa\right) \cdot \Lambda^{*}(1, \kappa) / 2+1\right. \\
& \geq z(2) f\left(e^{0}\left(\Lambda^{*}(1), 2, \kappa\right) \cdot \Lambda^{*}(1, \kappa) / 2+1\right.
\end{aligned}
$$

by virtue of Assumption $2(z(1) \geq z(2) / 2)$ and again, the properties of $e_{t}^{0}\left(\Lambda_{t}\left(s_{t}\right), s_{t}, \kappa_{t+1}^{e}\right)$. Suppose that in a particular period $t$ we have $\lambda_{t}(2, \kappa)=\lambda^{*}(1, \kappa)$. Then, the preceding observation implies $\lambda_{t+1}(2, \kappa) \leq \lambda^{*}(1, k)$. The second claim then follows at once. 


\section{Proof of Proposition 2:}

To examine the household's decisions, we form the Lagrangian for $s_{t}=1$ and $s_{t}=2$ :

$$
\begin{aligned}
\mathcal{L}\left(s_{t}\right)= & \left(3-s_{t}\right) c_{t}+\left(3-s_{t}\right) n_{t} \kappa_{t+1} \delta\left\{\ln \left(2 \bar{z} e_{t} \lambda_{t}+1+\zeta\right)\right\} \\
& +\mu\left\{\alpha\left(\left(3-s_{t}\right) \lambda_{t}+n_{t} \gamma\right)-\left(3-s_{t}+n_{t} \beta\right) c_{t}-n_{t} \alpha \gamma e_{t}\right\}
\end{aligned}
$$

The first-order conditions are:

$$
\begin{aligned}
& \frac{\partial \mathcal{L}}{\partial c_{t}}=\left(3-s_{t}\right)-\left(3-s_{t}+n_{t} \beta\right) \mu \leq 0, \quad c_{t} \geq c^{\min } \quad \text { complementarily } \\
& \frac{\partial \mathcal{L}}{\partial e_{t}}=\frac{\left(3-s_{t}\right) n_{t} \kappa_{t+1} \delta 2 \bar{z} \lambda_{t}}{2 \bar{z} e_{t} \lambda_{t}+1+\zeta}-\mu \alpha n_{t} \gamma \leq 0, \quad e_{t} \geq 0 \quad \text { complementarily }
\end{aligned}
$$

Assuming an interior solution, we have $\mu=\left(3-s_{t}\right) /\left(3-s_{t}+n_{t} \beta\right)$. Thus, we obtain the optimal choices $e_{t}^{0}\left(\Lambda_{t}\left(s_{t}\right), s_{t}, \kappa_{t+1}\right)$ as follows:

$$
e_{t}^{0}=\frac{2 \kappa_{t+1} \delta \bar{z} \lambda_{t}\left(3-s_{t}+n_{t} \beta\right)-\alpha \gamma(1+\zeta)}{2 \alpha \gamma \bar{z} \lambda_{t}}, s_{t}=1,2
$$

Noting that $\lambda_{t}=\Lambda_{t}\left(s_{t}\right) /\left(3-s_{t}\right)$,

$$
e_{t}^{0}\left(\Lambda_{t}\left(s_{t}\right), s_{t}, \kappa_{t+1}\right)=\frac{2 \kappa_{t+1} \delta \bar{z} \Lambda_{t}\left(s_{t}\right)\left(3-s_{t}+n_{t} \beta\right)-\alpha \gamma(1+\zeta)\left(3-s_{t}\right)}{2 \alpha \gamma \bar{z} \Lambda_{t}\left(s_{t}\right)}, \quad s_{t}=1,2
$$

Observe that $e_{t}^{0}\left(\Lambda_{t}(1), 1, \kappa_{t+1}\right)>e_{t}^{0}\left(\Lambda_{t}(2), 2, \kappa_{t+1}\right) \forall \lambda_{t}$ and $\forall \kappa_{t+1}$ as long as an interior solution holds for $s_{t}=2$. Obviously, $e_{t}^{0}\left(\Lambda_{t}\left(s_{t}\right), s_{t}, \kappa_{t+1}\right)$ is set to zero if (28) yields a negative number, and it is set to unity if (28) yields a number larger than 1 . The budget constraint yields the corresponding interior solution for an adult's consumption:

$$
c_{t}^{0}=\frac{-2 \kappa_{t+1} \delta \bar{z} \lambda_{t} n_{t}\left(3-s_{t}+n_{t} \beta\right)+\alpha \gamma n_{t}(1+\zeta)+2 \alpha \lambda_{t} \bar{z}\left(\left(3-s_{t}\right) \lambda_{t}+n_{t} \gamma\right)}{\left(3-s_{t}+n_{t} \beta\right) 2 \bar{z} \lambda_{t}},
$$

and again, with $\lambda_{t}=\Lambda_{t}\left(s_{t}\right) /\left(3-s_{t}\right)$, we have

$$
\begin{aligned}
c_{t}^{0}\left(\Lambda_{t}\left(s_{t}\right), s_{t}, \kappa_{t+1}\right)= & \frac{-2 \kappa_{t+1} \delta \bar{z} \Lambda_{t}\left(s_{t}\right) n_{t}\left(3-s_{t}+n_{t} \beta\right)+\alpha \gamma n_{t}(1+\zeta)\left(3-s_{t}\right)}{\left(3-s_{t}+n_{t} \beta\right) 2 \bar{z} \Lambda_{t}\left(s_{t}\right)}(29) \\
& +\frac{2 \alpha \bar{z} \Lambda_{t}\left(s_{t}\right)\left(\Lambda_{t}\left(s_{t}\right)+n_{t} \gamma\right)}{\left(3-s_{t}+n_{t} \beta\right) 2 \bar{z} \Lambda_{t}\left(s_{t}\right)}
\end{aligned}
$$




\section{Proof of Proposition 4:}

Suppose that $\lambda_{\tau}<\lambda^{*}\left(0, \kappa_{\tau}\right)$. The evolution of human capital is given by:

$$
\lambda_{\tau+1}=2 z\left(0, \kappa_{\tau}\right) f\left(e_{\tau}^{P}\left(2 \lambda_{\tau}, \kappa_{\tau}, \frac{\kappa_{\tau+1}}{\kappa_{\tau}}\right)\right) \lambda_{\tau}+1
$$

Since $\kappa_{\tau+1}<\kappa_{\tau}$ for $\tau<T$ and since $e_{\tau}^{P}$ is increasing with $\frac{\kappa_{\tau+1}}{\kappa_{\tau}}$

$$
\lambda_{\tau+1}<2 z\left(0, \kappa_{\tau}\right) f\left(e_{\tau}^{P}\left(2 \lambda_{\tau}, \kappa_{\tau}, 1\right) \lambda_{\tau}+1<\lambda_{\tau}\right.
$$

since $\lambda_{\tau}$ is below $\lambda^{*}\left(0, \kappa_{t}\right)$. Hence, a progressive decline sets in since $\lambda^{*}\left(0, \kappa_{t}\right) \leq \lambda^{*}\left(0, \kappa_{t+1}\right)$ for $t>\tau$.

For the second point we observe that

$$
\lambda_{T+1}=2 z(0, \underline{\kappa}) f\left(e_{T}^{P}\left(2 \lambda_{T}, \underline{\kappa}, \frac{\kappa_{T+1}}{\underline{\kappa}}\right) \lambda_{T}+1 \geq 2 z(0, \underline{\kappa}) f\left(e_{T}^{P}\left(2 \lambda_{T}, \underline{\kappa}, 1\right)\right) \lambda_{T}+1>\lambda_{T}\right.
$$

Hence, human capital will continue to grow after the peak of the disease. Repeating the argument for the next periods establishes the assertion.

\section{Proof of Proposition 5:}

Suppose $\lambda_{0}$ is sufficiently close to unity, with $2 \lambda_{0} \leq 2+\Delta$. We always have $e_{0}^{P}\left(2 \lambda_{0}, \kappa_{0}, \frac{\kappa_{1}}{\kappa_{0}}\right) \leq$ $e_{0}^{P}\left(2 \lambda_{0}, \kappa_{0}, 1\right)$ because $\kappa_{1}<\kappa_{0}$ according to condition (7). Hence, $e_{0}^{P}\left(2 \lambda_{0}, \kappa_{0}, \frac{\kappa_{1}}{\kappa_{0}}\right)=0$ if $2 \lambda_{0} \leq 2+\Delta$ according to Assumption 7. Hence, $\lambda_{1}=1$ and thus $\lambda_{t}=1 \quad \forall t \geq 1$.

From Assumption 11 we know that if $\lambda_{0}>\lambda^{a}(\underline{\kappa})$, then $e^{P}\left(\lambda_{0}, \kappa_{0}, \frac{\kappa_{1}}{\kappa_{0}}\right)=1$ and human capital will grow forever.

Furthermore, if $1<\lambda_{0}^{1}<\lambda_{0}^{2}$, then we have $\lambda_{t}^{1} \leq \lambda_{t}^{2} \quad \forall t \geq 1$ because of the properties of the function $e_{t}^{P}(\cdot, \cdot, \cdot)$. Therefore, if starting with $\lambda_{0}$ causes a collapse, then starting with $\tilde{\lambda}_{0}<\lambda_{0}$ also causes a collapse. On the other hand, if starting with $\lambda_{0}$ leads to sustainable growth, starting with $\tilde{\lambda}_{0}>\lambda_{0}$ also leads to sustainable growth. Then, the result follows by contradiction. 


\section{Proof of Proposition 6:}

We construct an example in the following way: we consider an epidemic pattern with $\hat{\kappa}_{t}=\hat{\kappa}$ for $t>T$ when the awareness efforts are undertaken. It is possible that

$$
e_{1}^{P}\left(2 \lambda_{1}, \kappa_{1}, \frac{1}{\kappa_{1}}\right)>e_{1}^{P}\left(2 \lambda_{1}, \hat{\kappa}_{1}, \frac{\hat{\kappa}_{2}}{\hat{\kappa}_{1}}\right)
$$

since $\hat{\kappa}_{1}>\kappa_{1}$ and $\frac{1}{\kappa_{1}}>\frac{\hat{\kappa}_{2}}{\hat{\kappa}_{1}}$ can hold simultaneously. ${ }^{12}$ Hence, human capital in $t=2$ will be higher when no awareness policies are introduced. If $\lambda_{2}$ under the awareness policy is smaller than $\lambda^{*}\left(0, \hat{\kappa}_{2}\right)$ then the economy will collapse as shown in Proposition 4. With no awareness policy, however, human capital may grow so much such that revised expectations at a later stage do not induce a collapse.

\footnotetext{
${ }^{12}$ It is straightforward to give specific examples.
} 


\section{References}

[1] Barro, R., and Sala-I-Martin, X. (1995), Economic Growth, New York: McGraw-Hill.

[2] Bell, C., and Gersbach, H. (2001), 'Child Labor and the Education of a Society', IZA Working Paper 338, Bonn.

[3] Bell, C., S. Devarajan, and Gersbach, H. (2003), 'The Long-run Economic Costs of AIDS: Theory and an Application to South Africa', Policy Research Working Paper 3152, World Bank, Washington, DC.

[4] Bell, C., S. Devarajan, and Gersbach, H. (2006), 'The Long-run Economic Costs of AIDS: A Model with an Application to South Africa', World Bank Economic Review, forthcoming.

[5] Bloom, D., and Canning, D. (2000), ' Health and the Wealth of Nations', Science, 287: 1207-9.

[6] Bloom, D., Canning, D., and Sevilla, J. (2001), 'The Effect of Health on Economic Growth: Theory and Evidence', NBER Working Paper, No. 8587.

[7] Bruhns, R. (2005), 'The Long-run Effects of HIV/AIDS in Kenya', South Asia Institute, University of Heidelberg, mimeo.

[8] Case, S.C., Paxson, C.H., and Ableidinger, J.D. (2002), 'Orphans in Africa', NBER Working Paper, No. 9213.

[9] Chakraborty, Shankha (2004), 'Endogenous Lifetime and Economic Growth', Journal of Economic Theory, 116(1), 119-137.

[10] Corrigan, P., Glomm, G., and Méndez, F. (2004), 'AIDS, Human Capital and Growth', mimeo, Indiana University, Bloomington, Indiana, USA.

[11] Cohn, S.K. (2003), The Black Death Transformed: Disease and Culture in Early Renaissance Europe, London: Arnold.

[12] Corrigan, P., Glomm, G., and Méndez, F. (2005), 'AIDS Crisis and Growth', Journal of Development Economics, 77 (1), 107-124. 
[13] Galor, O. and Weil, D. (1999), 'From Malthusian Stagnation to Modern Growth', American Economic Review, 89, 150-154.

[14] Galor, O. and Weil, D. (2000), 'Population, Technology, and Growth: From the Malthusian Regime to the Demographic Transition and Beyond', American Economic Review, 90, 806-828.

[15] Kalemli-Ozcan, S. (2006), 'AIDS; Reversal of the Demographic Transition and Economic Development: Evidence from Africa', University of Houston, mimeo.

[16] Lorentzen, P., McMillan, J., and Wacziarg, R. (2005), 'Death and Development', Graduate School of Business, Stanford University, mimeo.

[17] Lagerlöf, N.P. (2003), 'From Malthus to Modern Growth: Can Epidemics Explain the Three Regimes?', International Economic Review, 44(2), 755-777.

[18] Magruder, J. (2005), 'Marital Shopping and Epidemic AIDS', Preliminary Working Paper.

[19] McNeill, W.H. (1976), Plagues and Peoples, Chicago: Anchor Press.

[20] Mulder, T., and Johnson, P. (2005), 'Analysis of the Demographic Models Used to Incorporate HIV/AIDS Related Mortality', Paper presented at the International Union for the Scientific Study of Population (IUSSP), Tours, France, June 2005.

[21] Young, A. (2005), 'The Gift of the Dying: The Tragedy of AIDS and the Welfare of Future African Generations, Quarterly Journal of Economics, 120(2), 423-66. 


\section{Working Papers of the Center of Economic Research at ETH Zurich}

(PDF-files of the Working Papers can be downloaded at www.cer.ethz.ch/research).

06/57 C. Bell and H. Gersbach

Growth and Enduring Epidemic Diseases

06/56 H. Gersbach and M. Müller

Elections, Contracts and Markets

06/55 S. Valente

Intergenerational Transfers, Lifetime Welfare and Resource Preservation

06/54 H. Fehr-Duda, M. Schürer and R. Schubert

What Determines the Shape of the Probability Weighting Function?

06/53 S. Valente

Trade, Envy and Growth: International Status Seeking in a Two-Country World

06/52 K. Pittel

A Kuznets Curve for Recycling

06/51 C. N. Brunnschweiler

Cursing the blessings? Natural resource abundance, institutions, and economic growth

06/50 C. Di Maria and S. Valente

The Direction of Technical Change in Capital-Resource Economics

06/49 C. N. Brunnschweiler

Financing the alternative: renewable energy in developing and transition countries

06/48 S. Valente

Notes on Habit Formation and Socially Optimal Growth

06/47 L. Bretschger

Energy Prices, Growth, and the Channels in Between: Theory and Evidence

06/46 M. Schularick and T.M. Steger

Does Financial Integration Spur Economic Growth? New Evidence from the First Era of Financial Globalization

05/45 U. von Arx

Principle guided investing: The use of negative screens and its implications for green investors

05/44 Ch. Bjørnskov, A. Dreher and J.A.V. Fischer

The bigger the better? Evidence of the effect of government size on life satisfaction around the world

05/43 L. Bretschger

Taxes, Mobile Capital, and Economic Dynamics in a Globalising World 
05/42 S. Smulders, L. Bretschger and H. Egli

Economic Growth and the Diffusion of Clean Technologies: Explaining Environmental Kuznets Curves

05/41 S. Valente

Tax Policy and Human Capital Formation with Public Investment in Education

05/40 T.M. Steger and L. Bretschger

Globalization, the Volatility of Intermediate Goods Prices and Economic Growth

05/39 H. Egli

A New Approach to Pollution Modelling in Models of the Environmental Kuznets Curve

05/38 S. Valente

Genuine Dissaving and Optimal Growth

05/37 K. Pittel, J.-P. Amigues and T. Kuhn, Endogenous Growth and Recycling: A Material Balance Approach

05/36 L. Bretschger and K. Pittel

Innovative investments, natural resources, and intergenerational fairness: Are pension funds good for sustainable development?

04/35 T. Trimborn, K.-J. Koch and T.M. Steger

Multi-Dimensional Transitional Dynamics: A Simple Numerical Procedure

04/34 K. Pittel and D.T.G. Rübbelke

Private Provision of Public Goods: Incentives for Donations

04/33 H. Egli and T.M. Steger

A Simple Dynamic Model of the Environmental Kuznets Curve

04/32 L. Bretschger and T.M. Steger

The Dynamics of Economic Integration: Theory and Policy

04/31 H. Fehr-Duda, M. de Gennaro, R. Schubert

Gender, Financial Risk, and Probability Weights

03/30 T.M. Steger

Economic Growth and Sectoral Change under Resource Reallocation Costs

03/29 L. Bretschger

Natural resource scarcity and long-run development: central mechanisms when conditions are seemingly unfavourable

03/28 H. Egli

The Environmental Kuznets Curve - Evidence from Time Series Data for Germany

03/27 L. Bretschger

Economics of technological change and the natural environment: how effective are innovations as a remedy for resource scarcity? 
03/26 L. Bretschger, S. Smulders

Sustainability and substitution of exhaustible natural resources. How resource prices affect long-term R\&D-investments

03/25 T.M. Steger

On the Mechanics of Economic Convergence

03/24 L. Bretschger

Growth in a Globalised Economy: The Effects of Capital Taxes and Tax Competition

02/23 M. Gysler, J.Kruse and R. Schubert

Ambiguity and Gender Differences in Financial Decision Making: An Experimental Examination of Competence and Confidence Effects

01/22 S. Rutz

Minimum Participation Rules and the Effectiveness of Multilateral Environmental Agreements

01/21 M. Gysler, M. Powell, R. Schubert

How to Predict Gender-Differences in Choice Under Risk: A Case for the Use of Formalized Models

00/20 S.Rutz, T. Borek

International Environmental Negotiation: Does Coalition Size Matter?

00/19 S. Dietz

Does an environmental Kuznets curve exist for biodiversity? 